\title{
Pericyte Loss and Detachment in Experimental Cisplatin-Induced Neuropathy
}

\author{
Pérdida y Desprendimiento de Pericitos en la Neuropatía Experimental Inducida por Cisplatino
}

\author{
Depicha Jindatip; Worapat Nopparat; Phetnarin Kobutree; Atitaya Roumwong \& Sithiporn Agthong
}

JINDATIP, D.; NOPPARAT, W.; KOBUTREE, P.; ROUMWONG, A. \& AGTHONG, S. Pericyte loss and detachment in experimental cisplatin-induced neuropathy. Int. J. Morphol., 37(2):509-514, 2019.

SUMMARY: Cisplatin is an antineoplastic agent with neuropathy as one of its major side effect. However, effective treatment is lacking. Increasing evidence suggests that cisplatin might damage nerve capillaries leading to impaired functions of blood-nerve barrier (BNB) and neuropathy. This study was aimed to examine the effects of cisplatin on pericytes. Rats were either treated with intraperitoneal injection of cisplatin $2 \mathrm{mg} / \mathrm{kg}$ twice a week for five continuous weeks. Cisplatin-treated rats showed reduced body weight, thermal hypoalgesia and slow sciatic motor nerve conduction velocity, indicating neuropathy. The density of pericytes in the distal sciatic nerves determined by immunohistochemistry to desmin was significantly reduced in the cisplatin compared with that of the control groups. Electron microscopic analysis demonstrated the detachment of pericytes from endothelial cells including the disruption of shared basement membrane in the sciatic nerves from cisplatin-treated rats. These data indicate the pericyte loss and detachment caused by cisplatin. Future studies of the BNB components and functions after cisplatin treatment are needed and will be essential for the development of effective treatments against cisplatin-induced neuropathy.

KEY WORDS: Pericyte; Cisplatin; Nerve; Neuropathy.

\section{INTRODUCTION}

Cisplatin has been used as anti-neoplastic agent against cancers of various organs e.g. lung, head and neck, testis and ovary (Boulikas \& Vougiouka, 2004). However, it has several major side effects including peripheral neuropathy which can lead to cessation of chemotherapy. Cisplatin-induced neuropathy is characterized by sensory perception and nerve conduction deficits (Quasthoff \& Hartung, 2002; Authier et al., 2003). Demyelination is the main pathological abnormality in the nerves from cisplatintreated rats (Wongtawatchai et al., 2012; Al Moundhri et al., 2013; Agthong et al.,2015).

Current evidence suggests that vascular dysfunction might play a role in the cisplatin-induced neuropathy. Arterial occlusion was reported in patients treated with cisplatin-based chemotherapy (Li et al., 2006). In another study with patients, cisplatin also caused endothelial damage (Dieckmann et al., 2011). In rats treated with cisplatin, there were reduced nerve blood flow, decreased number of vasa nervorum and endothelial apoptosis (Kirchmair et al., 2005). Since pericytes cover the vascular wall and play an important role with endothelial cells in the functions of blood-nerve barrier (BNB)
(Peltonen et al., 2013), they might also be involved in the cisplatin-induced neuropathy. However, there was no direct study on the pericytes after cisplatin treatment. This study was the first to show that cisplatin administration in the rats reduced the density of pericytes and induced the separation of pericytes from the endothelial cells in the sciatic nerves.

\section{MATERIAL AND METHOD}

Animals. Fourteen male Wistar rats weighing 200-250 g were housed on a $12 \mathrm{~h}$ light-dark cycle with access to food and water ad libitum. The room temperature was maintained at $25 \pm 2{ }^{\circ} \mathrm{C}$. The experiment was approved by the institutional ethics committee (Ref. No. 19/58) and carried out in accordance with The Animals for Scientific Purposes Act 2015, Thailand.

Drug administration. The rats were randomly divided into 2 groups: control and cisplatin $(n=7$ each). The cisplatin group received cisplatin (Pfizer, USA) diluted in normal 
saline to the final concentration of $0.5 \mathrm{mg} / \mathrm{ml}$ for intraperitoneal injection. The dilution was done to give excess fluid to prevent nephrotoxicity. The dose of cisplatin was $2 \mathrm{mg} / \mathrm{kg}$ twice a week for five continuous weeks (20 $\mathrm{mg} / \mathrm{kg}$ cumulative dose). This dose regimen has been shown to induce peripheral neuropathy in rats (Authier et al.; Agthong et al.). The control group received normal saline injection with the volume and schedule equivalent to the cisplatin group.

Hind-paw thermal nociception. The details of procedure are described elsewhere (Wongtawatchai et al., 2012). Briefly, the test was done at baseline, the $3^{\text {rd }}$ and $5^{\text {th }}$ weeks. Each rat was placed on the hot plate analgesia meter (Harvard Apparatus, UK) maintained at $55^{\circ} \mathrm{C}$. When the rat licked its hind paw on either side, elapsed time was recorded as latency. The cut-off duration of $35 \mathrm{~s}$ was employed to avoid skin burn. The test was repeated at least 3 times with an interval of $15 \mathrm{~min}$ and mean latency was obtained for each rat.

Sciatic motor nerve conduction velocity. The motor nerve conduction velocity (MNCV) of sciatic nerve was measured at the $5^{\text {th }}$ week. The rat was anesthetized using isoflurane and rectal temperature was maintained at $37^{\circ} \mathrm{C}$ using a heating pad and digital rectal thermometer. The stimulating and recording needle electrodes were inserted at the sciatic notch and the second interosseous space of the hind foot, respectively. The ground electrode was placed at the lateral side of the hind foot. These electrodes were connected to the oscilloscope (Neurostar, Oxford Instrument). The sciatic nerve was stimulated with a supramaximal stimulus and compound muscle action potential (CMAP) was recorded. Latency was measured from the stimulation artifact to the positive peak of $\mathrm{M}$ wave. The average latency was derived from at least five stimulations. Then, the stimulating electrode was moved to the side of Achilles' tendon and the procedure was repeated to obtain the second latency. The $\mathrm{MNCV}$ was derived from dividing the distance between the two stimulation points by the latency difference.

Tissue collection. After the last injection of cisplatin, all the animals were sacrificed by overdose isoflurane and then transcardially perfused with $200 \mathrm{ml}$ of normal saline. In 5 rats per group, this was followed by $400 \mathrm{ml}$ of $4 \%$ paraformaldehyde (PFA) in $0.05 \mathrm{M}$ phosphate buffer (PB, $\mathrm{pH}$ 7.4). L4 DRG with the proximal and distal parts of sciatic nerves (divided at the trifurcation) were removed and immersed in the same fixative for $24 \mathrm{~h}$ at $4{ }^{\circ} \mathrm{C}$, followed by $30 \%$ sucrose in $0.05 \mathrm{M} \mathrm{PB}$ (pH 7.2) for 2 days. These specimens were subsequently processed for immunohistochemistry. In the remaining 2 rats per group, 2 $\%$ glutaraldehyde was used after normal saline instead of 4 $\%$ PFA. The DRG and nerves were removed and immersed in the same fixative for $2 \mathrm{~h}$ at $4{ }^{\circ} \mathrm{C}$. These specimens were further processed for ultrastructural analysis.

Immunohistochemistry. The specimens in $30 \%$ sucrose were embedded in Tissue-Tek compound (Sakura Finetechnical, Japan), frozen rapidly, and then transversely cut at $8 \mu \mathrm{m}$ in thickness for making 200 serial cryosections with a cryostat (Microm HM550; Thermo Fisher Scientific, Germany). Among 200 serial cryosections, the first of every ten sections were selected for immunohistochemical staining. Briefly, the sections were washed several times by phosphate-buffered saline (PBS) and incubated in PBS containing $2 \%$ normal goat serum for $20 \mathrm{~min}$ at $30^{\circ} \mathrm{C}$. Then, the tissues were incubated with anti-human desmin rabbit polyclonal antibody (1:1500, Abcam, Japan) overnight at room temperature, followed by biotinylated anti-rabbit IgG (Vector Laboratories, USA) for $30 \mathrm{~min}$ at $30^{\circ} \mathrm{C}$. An $\mathrm{ABC}$ method (Vector Laboratories) was performed in combination with 3,3'-diaminobenzidine (Dojindo Laboratories, Japan) for antigen detection. Luxol fast blue and cresyl violet were used to counterstain the nerve and DRG sections, respectively. Desmin was used as a marker of pericyte according to the previous studies (Fujiwara et al., 2010; Armulik et al., 2011; Sá-Pereira et al., 2012). In each selected section, the immunopositive staining in the whole crosssectional area was counted and the number was divided by the cross-sectional area to obtain the pericyte density $\left(/ \mathrm{mm}^{2}\right)$. Average density of proximal or distal nerve part was calculated from all selected sections of that part.

Transmission electron microscopy. The specimens in $2 \%$ glutaraldehyde were treated with $1 \% \mathrm{OsO}_{4}$, dehydrated with an alcohol series, and embedded in epoxy resin block. The ultrathin sections (70 nm thickness) were stained with lead citrate and uranyl acetate. Morphology of pericytes and the basement membrane shared with endothelial cells was observed with a transmission electron microscope (JEM1400PLUS; JEOL, Japan).

Statistical analysis. Student's t-test was used for comparing the body weight, thermal threshold, MNCV and pericyte density between the two groups. The test was done using SPSS for Windows version 23. Statistically significant differences were considered when $\mathrm{p}<0.05$.

\section{RESULTS}

Body weight. At baseline, the average body weight was similar between the two groups (Fig. 1). However, after the $2^{\text {nd }}$ until the $5^{\text {th }}$ weeks, the body weight of the cisplatin group was significantly decreased compared with that of the control group $(\mathrm{p}<0.001)$. 


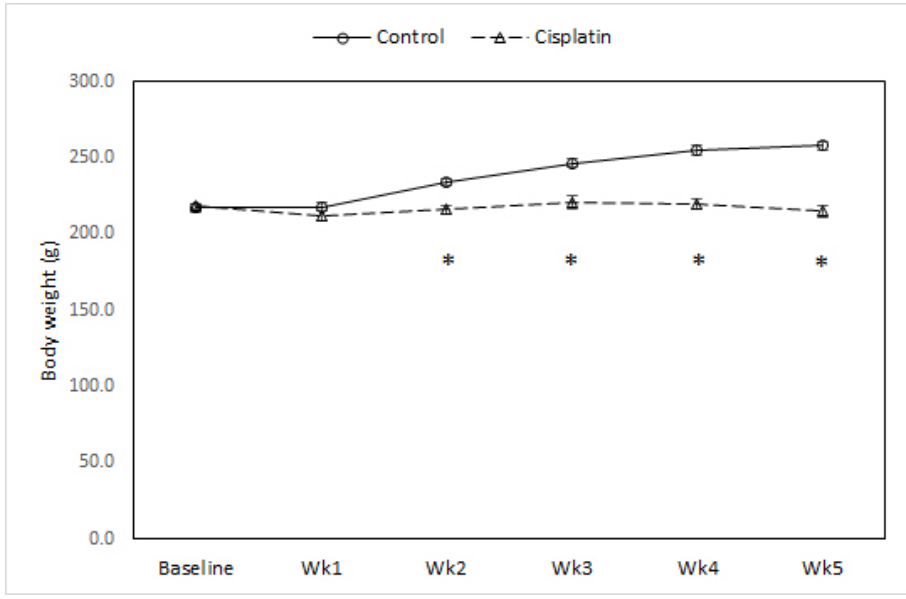

Fig. 1. Changes in the average body weight of the control and cisplatin groups. The graph shows means and SEM. Wk Week, ${ }^{*} \mathrm{p}<0.001$

Table I. Latency of thermal nociception at the hind paw.

\begin{tabular}{|c|c|c|c|}
\hline \multirow[t]{2}{*}{ Group } & \multicolumn{3}{|c|}{ Thermal latency (sec) } \\
\hline & Baseline & $3^{\text {rd }} \mathrm{W}_{\text {eek }}$ & $5^{\text {th }}$ week \\
\hline Control & $19.0 \pm 1.2$ & $17.3 \pm 1.0$ & $15.0 \pm 1.1$ \\
\hline Cisplatin & 16.5 & $20.8 \pm 1.0 *$ & $18.5 \pm 1.0 *$ \\
\hline
\end{tabular}

Data are means \pm SEM, $* \mathrm{p}<0.05$ vs. control

\section{Control}

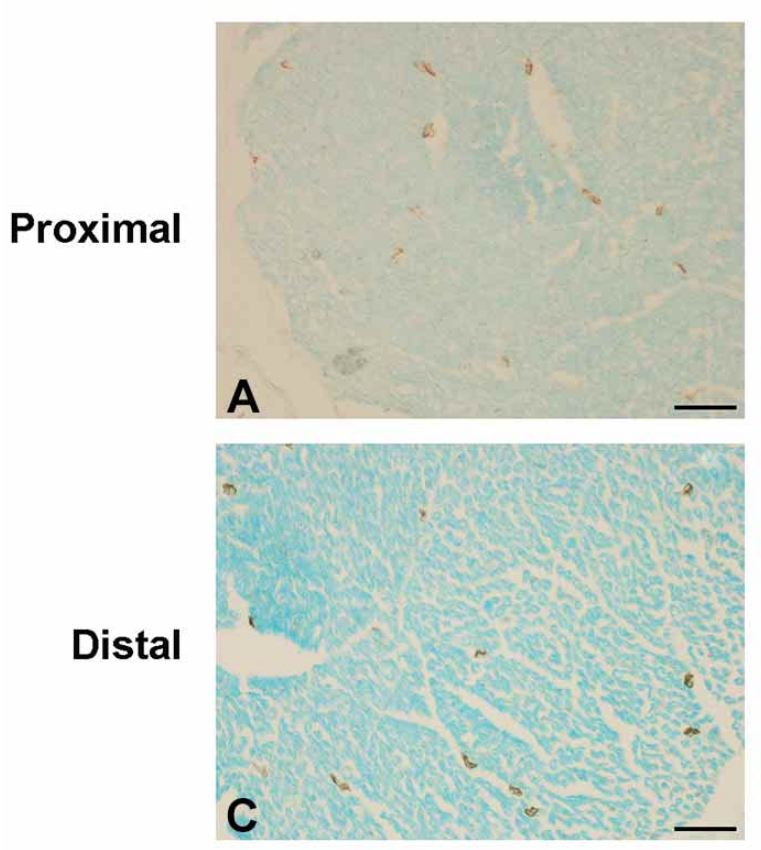

Hind-paw thermal nociception. Before the treatment, the latencies were not significantly different between the two groups (Table I). However, at the $3^{\text {rd }}$ and $5^{\text {th }}$ weeks, the latencies of the cisplatin were significantly longer than those of the control groups $(\mathrm{p}<0.05)$, indicating thermal hypoalgesia.

Sciatic MNCV. At the $5^{\text {th }}$ week, the average MNCV of the cisplatin group was $52.4 \pm 2.9(\mathrm{SEM}) \mathrm{m} / \mathrm{s}$ whereas the value of the control group was $74.4 \pm$ $4.2 \mathrm{~m} / \mathrm{s}$. The difference was statistically significant $(\mathrm{p}<0.001)$.

Pericyte density. Average pericyte density in the proximal sciatic nerve of the cisplatin was not significantly different from that of the control groups (Table II). In contrast, the value in the distal nerve of the cisplatin was significantly lower than that of the control groups. There were no significant differences in the density between the proximal and distal nerve parts in the same group. The representative images of immunopositive staining for pericytes in the proximal and distal nerves from the control and cisplatin groups are shown in Fig. 2. The staining was not counted in the DRG since several large blood vessels were also stained (arrows in Fig. 3) rendering the number of pericytes uncertain.

\section{Cisplatin}
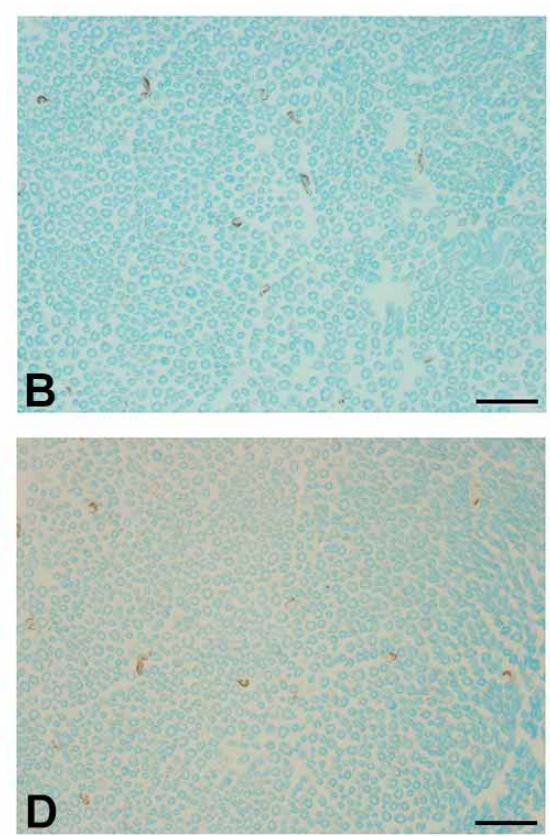

Fig. 2. Immunopositive staining of pericytes to desmin in the sciatic nerves from the control $(A, C)$ and cisplatin (B, D) groups. The densities of immunopositive cells in the proximal (B) and distal (D) parts in the cisplatin group tended to decrease. Scale bars $=50 \mu \mathrm{m}$ 
Table II. Pericyte density in the sciatic nerve.

\begin{tabular}{lcc}
\hline $\begin{array}{l}\text { Part of sciatic } \\
\text { nerve }\end{array}$ & \multicolumn{2}{c}{ Density of pericyte $\left(/ \mathrm{mm}^{2}\right)$} \\
Control & Cisplatin \\
\hline Proximal & $41.41 \pm 1.56$ & $33.37 \pm 3.79$ \\
Distal & $64.54 \pm 5.59$ & $32.86 \pm 4.53^{*}$ \\
\hline
\end{tabular}

Data are means $\pm \mathrm{SEM}, * \mathrm{p}<0.05$ vs. distal control.

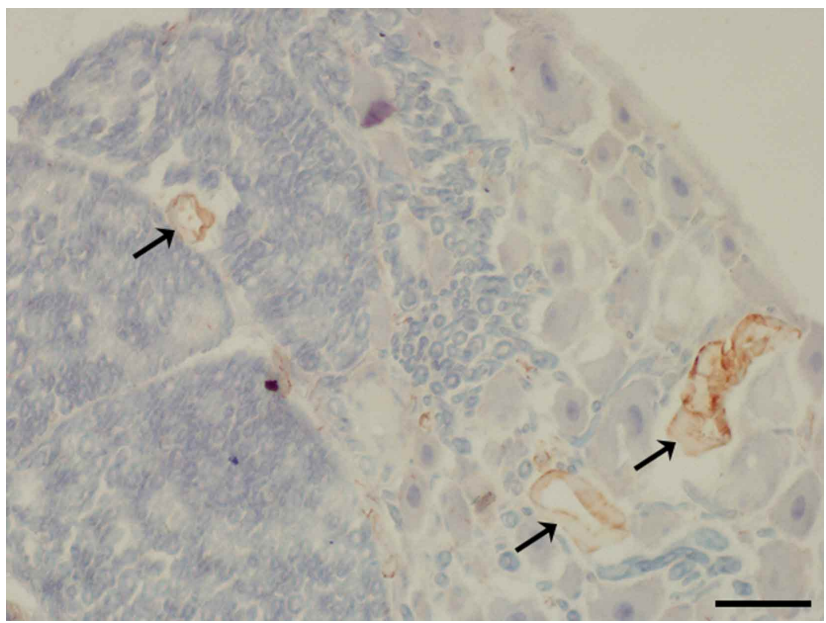

Fig. 3. Desmin immunoreactivity in the dorsal root ganglion. Arrows indicate the positive staining in the wall of large blood vessels. Scale bar $=50 \mu \mathrm{m}$.

Transmission electron microscopic analysis. In the proximal and distal parts of sciatic nerve from the control group, cell bodies and cytoplasmic processes of the pericytes wrapped around the endothelial cells with a shared basement membrane without any space between the two cell types (Fig. 4A and 4C). However, the detachment of pericytes from the endothelial cells was observed in the capillaries of sciatic nerves from the cisplatin group (Fig. 4B and 4D). Vascular basement membrane in the cisplatin group also became disrupted or absent compared to that of the control (Fig. 4B and 4D). In contrast, the findings in the DRG appeared normal in both groups (Fig. 4E and 4F). Other pathological findings such as accumulation of lysosomes or vacuoles were not observed in the pericytes as well as endothelial cells either in the control or cisplatin groups.

\section{DISCUSSION}

The results showed that cisplatin caused neuropathy characterized by weight loss, thermal hypoalgesia and impaired MNCV. These features of cisplatin-induced neuropathy in the rats have been previously reported (Authier et al.; Wongtawatchai et al., 2009, 2012; Al Moundhri et al.; Agthong et al.). Our previous studies using the same dose regimen of cisplatin also showed the pathological

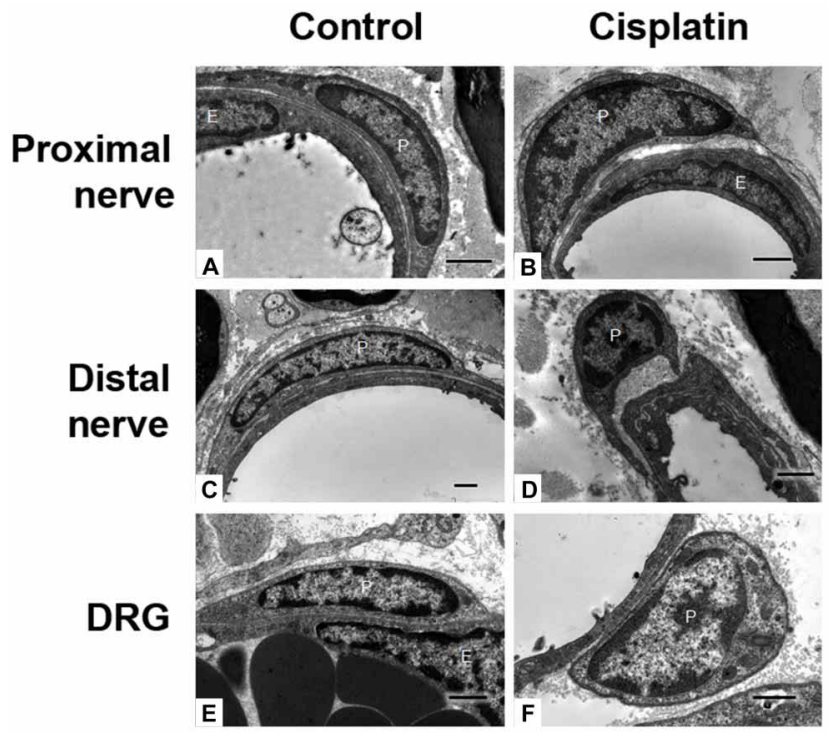

Fig. 4. Transmission electron microscopic images of pericytes from the control $(\mathrm{A}, \mathrm{C}, \mathrm{E})$ and cisplatin groups $(\mathrm{B}, \mathrm{D}, \mathrm{F})$ in the sciatic nerves (A-B; proximal part, C-D; distal part) and DRG (E-F). The split between pericytes and endothelial cells is apparent in the distal nerves from the cisplatin group. E; Endothelial cell, P; Pericyte. Scale bars $=1 \mu \mathrm{m}$.

changes in the nerve: loss of myelinated fibers, reduced diameter of myelinated axons and decreased myelin thickness (Wongtawatchai et al., 2009, 2012). Several of the above functional and pathological features were comparable to those observed in cancer patients treated with cisplatin (Roelofs et al., 1984; Thompson et al., 1984). Therefore, the pericytes in the DRG and sciatic nerve from the cisplatin group in this study were under the condition of neuropathy.

Anti-desmin antibody has been used to identify pericytes in several organs including brain and retina (ChanLing et al., 2004; Bell et al., 2010). The present study demonstrated that this marker was clearly seen around the capillaries in the endoneurium of sciatic nerve. This finding suggests that desmin is suitable for detecting pericytes in the peripheral nerve. From desmin immunohistochemistry, we found the significantly reduced density of pericytes in the distal nerves from the cisplatin compared with the control groups. It might appear that this was because the value in the distal nerve of the control group was high. This explanation was unlikely as the difference between the two nerve parts was not statistically significant. The reasons why the reduction was predominantly seen in the distal than the proximal nerves remain unknown. However, this correlates well with the more severe involvement of distal limbs seen in patients with cisplatin-induced neuropathy (Roelofs et al.; 
Thompson et al.). The lower density suggests pericyte loss likely due to migration. Detachment of pericytes from the endothelial cells in our EM results also supports this hypothesis. Pericyte detachment has been shown in various conditions and organs. Pericyte loss due to increased migration in the retina of diabetic rats was previously reported (Pfister et al., 2008). In the prolactinoma rat model, more pericytes in the anterior pituitary gland detached from the capillary walls than in the normal controls (Jindatip et al., 2018). Pericytes also migrated from the vascular wall in response to traumatic brain injury (Dore-Duffy et al., 2000). Therefore, our data suggest that pericytes migrate from the capillary walls in the nerves in response to cisplatin treatment.

Implications of the above ultrastructural abnormalities of pericytes, endothelial cells and vascular basement membrane are still unknown. However, since pericytes, endothelial cells and vascular basement membrane act as the BNB to regulate the vascular functions including permeability, these pathological changes are likely deleterious to the nerve. Shimizu et al. (2011a) showed that pericytes influenced the expression of claudin-5, an important component of the BNB, by endothelial cells through secretion of growth factors. Reduced level of claudin-5 was associated with BNB dysfunction in chronic inflammatory demyelinating polyradiculoneuropathy (CIDP) (Kanda et al., 2004). Besides claudin-5, nerve pericytes also express other important components of the $\mathrm{BNB}$, for example, fibronectin, collagen type IV (Shimizu et al., 2011b). These data suggest that pericytes as well as endothelial cells are important for the normal functions of BNB and damage in any of these components might cause neuropathy. Regarding cisplatin-induced neuropathy, results from the previous studies suggest that vascular dysfunction might play an important role in this pathological condition. Occlusion of cerebral arteries was observed in the patients treated with cisplatin-based chemotherapy ( $\mathrm{Li}$ et al.). Cisplatin also caused endothelial damage indicated by increased serum level of von Willebrand factor in the patients receiving chemotherapy (Dieckmann et al.). In rats treated with cisplatin, reduced nerve blood flow, decreased number of vasa nervorum and endothelial apoptosis were observed (Kirchmair et al.). The results of this study also suggest that cisplatin adversely affects the pericytes resulting in further dysfunction of BNB. Future studies are needed to examine the effects of cisplatin on the expression of BNB components e.g. claudin-5 and BNB functions.

To our knowledge, this study was the first to demonstrate the reduced density and detachment of pericytes from endothelial cells in the nerves from rats with cisplatininduced neuropathy. Disruption of vascular basement membrane was also observed. These changes might result in impaired BNB which needs to be proved. These data are important for understanding the pathological mechanisms underlying cisplatin-induced neuropathy and developing novel potential treatments.

\section{ACKNOWLEDGEMENTS}

We are grateful to the Research Affairs, Faculty of Medicine, Chulalongkorn University for assistance regarding transmission electron microscopy. This work was supported by the Faculty of Medicine, Chulalongkorn University under Rachadaphiseksomphot Fund 2016 (RA59/044).

JINDATIP，D.; NOPPARAT，W.; KOBUTREE，P.; ROUMWONG, A. \& AGTHONG, S. Pérdida y desprendimiento de pericitos en la neuropatía experimental inducida por cisplatino. Int. J. Morphol., 37(2):509-514, 2019.

RESUMEN: El cisplatino es un agente antineoplásico y presenta como uno de sus principales efectos secundarios, la neuropatía. Sin embargo, falta un tratamiento eficaz. La creciente evidencia sugiere que el cisplatino podría dañar los capilares nerviosos, lo que puede provocar una alteración de las funciones de la barrera hematoencefálica (BHE) y neuropatía. Este estudio tuvo como objetivo examinar los efectos del cisplatino en los pericitos. Las ratas se trataron con inyección intraperitoneal de cisplatino (2 $\mathrm{mg} / \mathrm{kg}$ ) dos veces por semana durante 5 semanas seguidas. Las ratas tratadas con cisplatino mostraron una reducción del peso corporal, hipoalgesia térmica y una velocidad de conducción del nervio ciático lenta, lo que indicaría neuropatía. La densidad de los pericitos en los nervios ciáticos distales determinada por inmunohistoquímica para desmina se redujo significativamente en el grupo cisplatino en comparación con la de los grupos controles. El análisis al microscopio electrónico demostró el desprendimiento de pericitos de las células endoteliales, incluida la ruptura de la membrana basal compartida en los nervios ciáticos de ratas tratadas con cisplatino. Estos datos indican la pérdida de pericitos y el desprendimiento causado por el cisplatino. Se necesitan estudios futuros de los componentes y funciones del BHE después del tratamiento con cisplatino y serán esenciales para el desarrollo de tratamientos efectivos contra la neuropatía inducida por el cisplatino.

PALABRAS CLAVE: Pericito; Cisplatino; Nervio; Neuropatía.

\section{REFERENCES}

Agthong, S.; Kaewsema, A. \& Charoensub, T. Curcumin ameliorates functional and structural abnormalities in cisplatin-induced neuropathy. Exp. Neurobiol., 24(2):139-45, 2015. 
Al Moundhri, M. S.; Al-Salam, S.; Al Mahrouqee, A.; Beegam, S. \& Ali, B. H. The effect of curcumin on oxaliplatin and cisplatin neurotoxicity in rats: some behavioral, biochemical, and histopathological studies. $J$. Med. Toxicol., 9(1):25-33, 2013.

Armulik, A.; Genové, G. \& Betsholtz, C. Pericytes: developmental, physiological, and pathological perspectives, problems, and promises. Dev. Cell, 21(2):193-215, 2011.

Authier, N.; Gillet, J. P.; Fialip, J.; Eschalier, A. \& Coudore, F. An animal model of nociceptive peripheral neuropathy following repeated cisplatin injections. Exp. Neurol., 182(1):12-20, 2003.

Bell, R. D.; Winkler, E. A.; Sagare, A. P.; Singh, I.; LaRue, B.; Deane, R. \& Zlokovic, B. V. Pericytes control key neurovascular functions and neuronal phenotype in the adult brain and during brain aging. Neuron, 68(3):409-27, 2010.

Boulikas, T. \& Vougiouka, M. Recent clinical trials using cisplatin, carboplatin and their combination chemotherapy drugs (review). Oncol. Rep., 11(3):559-95, 2004.

Chan-Ling, T.; Page, M. P.; Gardiner, T.; Baxter, L.; Rosinova, E. \& Hughes, $\mathrm{S}$. Desmin ensheathment ratio as an indicator of vessel stability: evidence in normal development and in retinopathy of prematurity. Am. J. Pathol., 165(4):1301-13, 2004.

Dieckmann, K. P.; Struss, W. J. \& Budde, U. Evidence for acute vascular toxicity of cisplatin-based chemotherapy in patients with germ cell tumour. Anticancer Res., 31(12):4501-5, 2011.

Dore-Duffy, P.; Owen, C.; Balabanov, R.; Murphy, S.; Beaumont, T. \& Rafols, J. A. Pericyte migration from the vascular wall in response to traumatic brain injury. Microvasc. Res., 60(1):55-69, 2000.

Fujiwara, K.; Jindatip, D.; Kikuchi, M. \& Yashiro, T. In situ hybridization reveals that type I and III collagens are produced by pericytes in the anterior pituitary gland of rats. Cell Tissue Res., 342(3):491-5, 2010.

Jindatip, D.; Fujiwara, K.; Sarachana, T.; Mutirangura, A. \& Yashiro, T. Characteristics of pericytes in diethylstilbestrol (DES)-induced pituitary prolactinoma in rats. Med. Mol. Morphol., 51(3):147-55, 2018.

Kanda, T.; Numata, Y. \& Mizusawa, H. Chronic inflammatory demyelinating polyneuropathy: decreased claudin- 5 and relocated ZO1. J. Neurol. Neurosurg. Psychiatry, 75(5):765-9, 2004.

Kirchmair, R.; Walter, D. H.; Ii, M.; Rittig, K.; Tietz, A. B.; Murayama, T.; Emanueli, C.; Silver, M.; Wecker, A.; Amant, C. et al. Antiangiogenesis mediates cisplatin-induced peripheral neuropathy: attenuation or reversal by local vascular endothelial growth factor gene therapy without augmenting tumor growth. Circulation, 111(20):2662-70, 2005.

Li, S. H.; Chen, W. H.; Tang, Y.; Rau, K. M.; Chen, Y. Y.; Huang, T. L.; Liu, J. S. \& Huang, C. H. Incidence of ischemic stroke post-chemotherapy: a retrospective review of 10,963 patients. Clin. Neurol. Neurosurg., 108(2):150-6, 2006.

Peltonen, S.; Alanne, M. \& Peltonen, J. Barriers of the peripheral nerve. Tissue Barriers, 1(3):e24956, 2013.

Pfister, F.; Feng, Y.; vom Hagen, F.; Hoffmann, S.; Molema, G.; Hillebrands, J. L.; Shani, M.; Deutsch, U. \& Hammes, H. P. Pericyte migration: a novel mechanism of pericyte loss in experimental diabetic retinopathy. Diabetes, 57(9):2495-502, 2008.

Quasthoff, S. \& Hartung, H. P. Chemotherapy-induced peripheral neuropathy. J. Neurol., 249(1):9-17, 2002.

Roelofs, R. I.; Hrushesky, W.; Rogin, J. \& Rosenberg, L. Peripheral sensory neuropathy and cisplatin chemotherapy. Neurology, 34(7):934-8, 1984.

Sá-Pereira, I.; Brites, D. \& Brito, M. A. Neurovascular unit: a focus on pericytes. Mol. Neurobiol., 45(2):327-47, 2012.

Shimizu, F.; Sano, Y.; Abe, M. A.; Maeda, T.; Ohtsuki, S.; Terasaki, T. \& Kanda, T. Peripheral nerve pericytes modify the blood-nerve barrier function and tight junctional molecules through the secretion of various soluble factors. J. Cell. Physiol., 226(1):255-66, 2011a.

Shimizu, F.; Sano, Y.; Haruki, H. \& Kanda, T. Advanced glycation endproducts induce basement membrane hypertrophy in endoneurial microvessels and disrupt the blood-nerve barrier by stimulating the release of TGF-b and vascular endothelial growth factor (VEGF) by pericytes. Diabetologia, 54(6):1517-26, $2011 \mathrm{~b}$.
Thompson, S. W.; Davis, L. E.; Kornfeld, M.; Hilgers, R. D. \& Standefer, J. C. Cisplatin neuropathy. Clinical, electrophysiologic, morphologic, and toxicologic studies. Cancer, 54(7): 1269-75, 1984.

Wongtawatchai, T.; Agthong, S.; Kaewsema, A. \& Chentanez V. Sex-related differences in cisplatin-induced neuropathy in rats. J. Med. Assoc. Thai., 92(11):1485-91, 2009.

Wongtawatchai, T.; Agthong, S.; Kaewsema, A. \& Chentanez, V. Altered phosphorylation of mitogen-activated protein kinases in dorsal root ganglia and sciatic nerve of rats with cisplatin-induced neuropathy. Asian Biomed., 6(3):397-411, 2012.
Corresponding author:
Dr. Sithiporn Agthong
Department of Anatomy
Faculty of Medicine
Chulalongkorn University
Rama IV Road
Pathumwan
Bangkok
THAILAND

Email: sagthong@hotmail.com

Received: 30-09-2018

Accepted: 28-01-2019 